
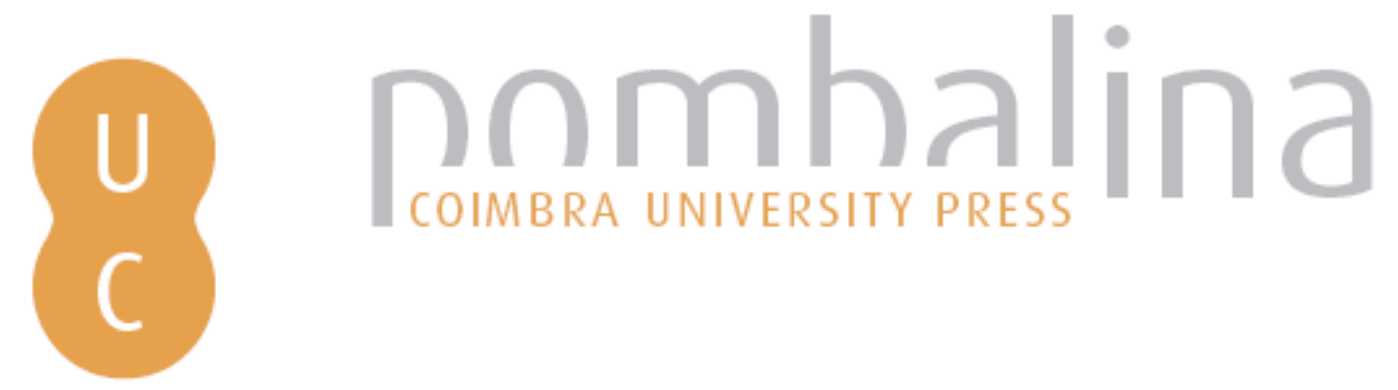

\title{
Educação e formação de adultos: nótulas sobre a necessidade de descomprometer a Cinderela depois do beijo do Príncipe Encantado
}
Autor(es):
Alcoforado, Luís; Ferreira, Sónia Mairos
Publicado por: Imprensa da Universidade de Coimbra
URL
persistente:
URI:http://hdl.handle.net/10316.2/31222
DOI:
DOI:http://dx.doi.org/10.14195/978-989-26-0228-8_1
Accessed : $\quad$ 26-Apr-2023 15:43:28

A navegação consulta e descarregamento dos títulos inseridos nas Bibliotecas Digitais UC Digitalis, UC Pombalina e UC Impactum, pressupõem a aceitação plena e sem reservas dos Termos e Condições de Uso destas Bibliotecas Digitais, disponíveis em https://digitalis.uc.pt/pt-pt/termos.

Conforme exposto nos referidos Termos e Condições de Uso, o descarregamento de títulos de acesso restrito requer uma licença válida de autorização devendo o utilizador aceder ao(s) documento(s) a partir de um endereço de IP da instituição detentora da supramencionada licença.

Ao utilizador é apenas permitido o descarregamento para uso pessoal, pelo que o emprego do(s) título(s) descarregado(s) para outro fim, designadamente comercial, carece de autorização do respetivo autor ou editor da obra.

Na medida em que todas as obras da UC Digitalis se encontram protegidas pelo Código do Direito de Autor e Direitos Conexos e demais legislação aplicável, toda a cópia, parcial ou total, deste documento, nos casos em que é legalmente admitida, deverá conter ou fazer-se acompanhar por este aviso.

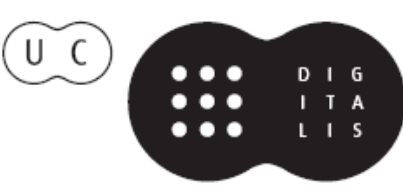




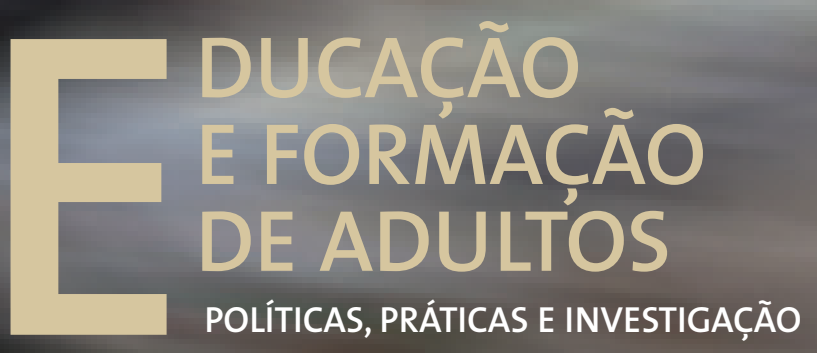

Luís Alcoforado • Joaquim Armando G. Ferreira António Gomes Ferreira • Margarida Pedroso de Lima Cristina Vieira • Albertina L. Oliveira • Sónia Mairos Ferreira 


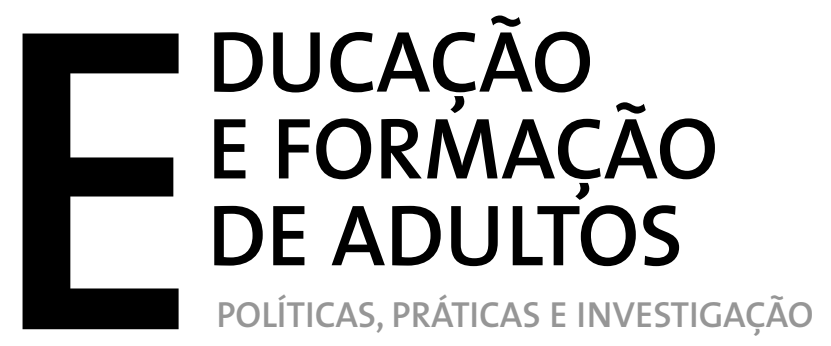

Luís Alcoforado • Joaquim Armando G. Ferreira António Gomes Ferreira - Margarida Pedroso de Lima Cristina Vieira • Albertina L. Oliveira • Sónia Mairos Ferreira 
EDIÇÃo

Imprensa da Universidade de Coimbra

URL: http://www.uc.pt/imprensa_uc

Vendas online: http://www.livrariadaimprensa.com

CONCEPÇÃO GRÁFICA

António Barros

Pré-Impressáo

SerSilito-Empresa Gráfica, Lda

EXECUÇÃo GRÁFICA

SerSilito-Empresa Gráfica, Lda

ISBN

978-989-26-0136-6

DePósito LEgaL

$340309 / 12$ 

INTRODUÇÃo GERAL

EducaÇão e Formação de Adultos: nótulas sobre a necessidade de descomprometer a Cinderela depois do beijo do Príncipe Encantado

Luís Alcoforado

Sónia Mairos Ferreira

Universidade de Coimbra

\begin{abstract}
Por um lado, a Aprendizagem ao Longo da Vida aparece como um príncipe encantado, disposto a resgatar a Cinderela (Educaçấo de Adultos) negligenciada, da periferia das políticas da educação. Por outro lado, este debate aparece como uma ameaça às estruturas existentes da Educação de Adultos, não só porque vem dominado por preocupaçôes económicas e profissionais, mas também porque promove uma visão fragmentada e dividida da aprendizagem (Field, 2002, p.14).
\end{abstract}

\title{
1. Educação e Formação de Adultos: perspectivas históricas e identitárias
}

Antes de se afirmar na retórica dos discursos políticos e de gestão mais recentes, a Aprendizagem ao Longo da Vida foi, desde o início da história da humanidade, uma constatação óbvia! Como muito mais tarde demonstraram sociólogos e antropólogos, a partir de estudos com sociedades primitivas, a mudança mais imediata, empreendida por qualquer comunidade, apenas poderia ocorrer em função da mudança estável dos comportamentos das populaçóes adultas, uma vez que somente estas detinham as características necessárias para se adaptarem e provocarem qualquer tipo de transformaçóes com impacto na vida conjunta. Com rigor, se dos processos iniciáticos de socialização que, de forma tradicional e transversal a diferentes períodos e culturas, marcavam a preparação da infância, adolescência e juventude, para a plena integração numa comunidade determinada, poderíamos esperar, para o futuro, uma evolução cultural desejável, a capacidade de lidar com situaçóes não esperadas e a necessidade de construir, em cada momento, a melhor solução de suporte ao desenvolvimento de um bem-estar comum, apenas dependia da capacidade de homens e mulheres para reconstruir a realidade a partir das suas experiências e saberes precedentes.

Se é verdade que a complexificação das formas sociais de vida veio exigir um nível muito mais elevado de organização na preparação de futuros cidadãos, também não resultou menos evidente a necessidade de potenciar as aprendizagens das pessoas adultas, almejando torná-las capazes de conduzir a sua história, no sentido dos seus anseios comuns. A emergência da modernidade veio colocar esta necessidade no âmbito de uma verdadeira tarefa civilizacional. Entendida por Habermas (2000, p. 14), como "a formação do capital e mobilização de recursos, o desenvolvimento das forças produtivas e o aumento da pro- 
dutividade do trabalho, o estabelecimento dos poderes políticos centralizados e a formação de identidades nacionais, a expansão de direitos de participação política, de formas urbanas de vida e de formação escolar formal e a secularização de valores e normas", esta nova era veio obrigar ao domínio de saberes progressivamente mais complexos e integrados e consagrar a procura social da educação.

Assim, o triunfo da escola, enquanto espaço e tempo de educação formal, indispensável à construção de sociedades sucessivamente mais desenvolvidas, ocorreu sobre a convicção generalizada de que era obrigatório encontrar uma dimensão ideológica que traduzisse os valores e os saberes fundacionais de uma determinada sociedade e uma dimensão tecnológica que disponibilizasse os recursos necessários para aplanar o caminho certo para essa contínua construção colectiva (Bhola, 1989). Cedo se percebeu, também, que este espaço e tempo não se podia reduzir a uma idade da vida, tal como não poderia ter características únicas para todas essas idades. Traduzindo este sentimento, alguns pensadores e especialistas dos fenómenos educativos, souberam assumir a responsabilidade, algo messiânica, de nos alertar para a(s) escola(s) que necessitávamos edificar. De entre todos os contributos, teremos de encontrar um merecido destaque para o pedagogo checo João Amós Coménio (1592-1670) que na sua Pampaedia nos mostra, com argumentaçáo cristalina, a necessidade, a possibilidade e a facilidade de todos os homens serem educados totalmente, em todas as coisas. Esta educaçáo universal seria, no entanto, desenvolvida de acordo com a especificidade de cada idade da vida, compreendendo a formação pré-natal, da infância, da puerícia, da adolescência, da juventude, da idade adulta, da velhice e da morte.

Para o caso do adulto, entendido como o "que atingiu o ponto máximo do seu desenvolvimento e das suas forças, está apto para conduzir as suas tarefas e começa já a praticar o género de vida para que se preparou", defende-se uma escola onde, doravante, todos sejam mestres e discípulos, pelo que "já não deve aprender-se mediante meros prelúdios, mas mediante acçóes sérias”, numa escola que, diferentemente das anteriores, deve consistir no "contacto directo com as coisas e nas múltiplas relaçóes com os homens durante todo o resto da vida" (Coménio, 1971, pp. 301-302). Certificando-se de que desta escola ninguém pode ficar afastado, o mesmo autor lança, na página seguinte, um veemente apelo: "vinde, pois, ó jovens que deixastes as escolas, e aprendei agora a ser navegantes no próprio mar da vida e das actividades humanas! Aprendei a agir como homens e a administrar por vós mesmos as vossas coisas com vontade decidida, mas com prudência”.

Se resultava evidente que a nova era, e o cidadão que ela convocava, não surgiriam sem uma aposta continuada em actividades educativas com os fins e meios de especificidade própria a cada idade da vida, a emergência dos ideais da democracia e da igualdade de direitos, deveres e oportunidades, tornaram mais evidente a necessidade de um investimento concertado numa oferta educativa, para pessoas adultas, que atravessasse todos os seus tempos e espaços de vida. Se a estas legítimas aspiraçôes civilizacionais acrescentarmos as necessidades de saberes e mudança relacionados com o trabalho, entretanto transformado em tempo social dominante, à volta do qual se passaram a organizar todos os outros momentos da vida (Sue, 2001), perceberemos a multiplicidade de iniciativas que foram surgindo, principalmente ao longo de todo o século XIX, algumas mais próximas dos objectivos e dos modelos escolares emergentes, enquanto muitas outras empreenderam caminhos mais ousados e inovadores, ganhando corpo e sentido nas organizaçóes de ensino mútuo, nas instituiçôes de educação operária, ou cooperativas, e nos movimentos e associações de educação popular. 
Numa tentativa de sistematização possível, De Natale (2003, p. 48) regista, pelo menos, dois grandes modelos de desenvolvimento de práticas educativas, para pessoas adultas, que, cada um à sua maneira, tiveram uma influência significativa na sua evoluçáo posterior. $O$ primeiro tem uma matriz essencialmente inglesa, mas acabou por ser assumido, predominantemente, pela generalidade dos países da Europa central, colocando ênfase particular numa Educação de Adultos, "entendida como intervenção extraordinária, de carácter técnico e profissional e como instrumento de promoção social e de formação periódica”. O segundo modelo teve origem no pensamento e acçáa do bispo dinamarquês N. F. S. Grundtvig, para quem era indispensável construir uma Educação de Adultos essencialmente dirigida, "tanto para a consolidaçáo da personalidade e para a elevação pessoal, como para o contínuo progresso e fortalecimento de uma organizaçáo social e democrática, inspirada no mais absoluto respeito das liberdades subjectivas".

A estes dois modelos corresponderam, como seria natural, dois diferentes entendimentos de tempos e espaços educativos. Num caso, optou-se pela valorização de lugares educativos especializados, algumas vezes organizados em rede, que procuravam a promoçáo social dos operários, como base para a construçáo de novas sociedades. Noutro caso, tudo foi pensado à volta da ideia central de uma educação à roda da vida, reforçando, particularmente, a importância da família e das comunidades de maior vizinhança, como espaços educativos.

O sucesso de algumas destas iniciativas e a importância das conquistas dos movimentos sociais que, em muitos casos, lhes davam sentido e consistência ideológica, acabaram por elevar a responsabilidade atribuída à educação de adultos, vinculando-a a missóes ciclópicas, ao nível cognitivo, social, profissional, político e cultural, de tal modo que, no final do segundo grande conflito mundial do século XX, a Organização das Naçóes Unidas para a Educação Ciência e Cultura (UNESCO), olha para este campo com a convicção genuína de quem espera os contributos necessários para uma nova ordem e uma diferente vida à escala planetária. Exortando os países membros, reunidos numa conferência internacional sobre esta temática, a um forte investimento em políticas públicas que favorecessem a proliferaçáo de práticas, a UNESCO acreditava, em termos gerais, que da Educaçáo de Adultos se poderia esperar um decisivo contributo para a prossecução dos seguintes objectivos: favorecer os movimentos que procurassem uma cultura comum, contribuindo para eliminar o contraste entre massas e elites; estimular o espírito de democracia e tolerância; restituir, principalmente aos jovens, a confiança, após a desordem mundial; restaurar o sentido de comunidade numa época de dispersão; desenvolver e clarificar o sentido de pertença a uma comunidade mundial; contribuir para a promoção da paz e para instaurar uma civilização mais completa e mais humana; contribuir para a erradicação da pobreza, integrando programas de assistência técnica aos países em desenvolvimento. Em resumo, retomando o espírito mais original que justificava estas apostas educativas, como era necessário empreender mudanças impressivas, e estas nunca aconteceriam sem a transformação dos modos de agir das pessoas adultas, esta área assumia foros de absoluta charneira nos processos de desenvolvimento integrado que urgia encetar.

Do ponto de vista das políticas, da organização, das metodologias e da avaliaçáo, o pensamento predominante procura fazer uma síntese entre os dois modelos enunciados: reafirma a importância das experiências de educação comunitária e, em simultâneo, procura garantir a todas as pessoas adultas o direito a uma educaçáo formal e não formal que lhes permitisse uma ascensão na pirâmide social, por força da ascensão na pirâmide dos níveis de escolaridade. No entanto, era pacífico aceitar que todas estas experiências se deviam afastar dos modelos escolares, exortando-se as Universidades a contribuírem para a edificação de 
um novo campo de construção de conhecimento que pudesse trazer implicaçóes para uma prática em permanente renovação.

Desta dinâmica interdependente foram surgindo projectos inovadores, estudos sistemáticos e políticas públicas, que culminaram, no início da década de setenta do século vinte, numa proposta de Educação Permanente que se pretendia verdadeiramente revolucionária, face aos referenciais vigentes. Justificada por razóes epistemológicas, culturais, tecnológicas e profissionais (Osorio, 2003), esta proposta assumia como inevitavelmente educativas todas as experiências de vida dos seres humanos, sendo, por isso mesmo, necessário garantir igualdade de oportunidades de envolvimento em práticas enriquecedoras, acompanhando-as de um apoio especializado que, no limite, habilitasse todos/as para autodirigirem os seus próprios percursos de formação e de vida (Simôes, 1979).

Surgida num ambiente de forte optimismo desenvolvimentista, de que procurava constituir-se como uma modelação humanizadora, e incluída nos processos de construção dos estados de bem-estar social, a Educação Permanente acabou por consagrar, pelo menos, três pontos de não retorno, no debate educativo contemporâneo, no que à educação (e formação) de adultos diz respeito: progressivamente, as políticas públicas começaram a garantir o direito de todas as pessoas à educaçáo, ao longo de toda a vida; o conflito passou, também, a ser um dos principais organizadores dos processos de educação, uma vez que todos os tempos e espaços da vida eram educativos; a necessidade de consagrar mecanismos de ajuda às pessoas nos processos algo complexos de se confrontarem com os seus adquiridos, construírem os seus projectos de vida e satisfazerem as suas necessidades educativas, como resposta a uma procura informada, ao nível individual e social. Para que todas estas componentes pudessem funcionar de forma verdadeiramente articulada e os objectivos fossem conseguidos, através dos processos mais adequados, ficava, mais uma vez, muito claro, que este campo de práticas e de construção de conhecimento necessitava de afirmar a sua especificidade e de mobilizar profissionais próprios que servissem essa identidade.

Confrontado com as quebras de competitividade das economias ocidentais e com os debates sobre a produtividade do trabalho, ao longo dos anos setenta e oitenta, este projecto educativo, global e unificador, de raiz humanista, vocacionado para um desenvolvimento integrado e para a promoçáo do bem-estar das pessoas e das suas comunidades, vê-se totalitariamente manietado por práticas de formação profissional que visavam gerir os mercados de emprego e promover a saúde económica das empresas, dos países e dos blocos transnacionais emergentes.

A formação transformou-se, mesmo, num dos grandes mitos do final do século vinte! Tudo o que corria menos bem poderia ser resolvido através de uma aposta na aprendizagem, agora com uma dimensão muito mais individual e com um sentido mais instrumental de aumento da competitividade, satisfação das necessidades das empresas e incremento da empregabilidade. Arrastada no turbilhão da globalização económica e de regressão das conquistas dos estados de bem-estar social, a Educação de Adultos viu-se, assim, esmagadoramente utilizada em práticas formativas de promoção da empregabilidade, esperando-se que providenciasse os recursos necessários ao sucesso, na escalada progressiva da competiçáo entre pessoas pelo êxito dos seus projectos pessoais e profissionais. Como a empregabilidade é, antes de tudo, uma responsabilidade individual, os estados deviam assumir a obrigação de garantir uma qualificação social mínima a todos/as os/as cidadãos/ âs, devendo todas as outras iniciativas de incremento de saberes e aptidóes individuais ser suportadas por quem delas beneficiasse. 
É, entấo, neste quadro de predomínio conceptual da aprendizagem com incidência mais individualista, fragmentada e instrumental, de defesa de um papel mínimo do estado e de um apelo progressivo ao mercado (Jarvis, 2001; Lima, 2003) que surge a nova proposta da Aprendizagem ao Longo da Vida. Emoldurada por estes novos discursos e pelos ciclos cada vez menos previsíveis dos mercados de trabalho, a Educação e Formação de Adultos tem vindo a revelar, ao longo das últimas décadas, uma dinâmica e uma capacidade de influência incontornáveis, quer enquanto campo de práticas, quer como domínio de construçáo e transferência de conhecimento. Isto acontece porque, em primeiro lugar, tem registado um incremento exponencial da oferta e da procura, provocando investimentos crescentes, políticas diversificadas e o envolvimento progressivo de múltiplos agentes e, em segundo lugar, porque foi sendo desafiada a constituir-se como disciplina universitária, da qual se têm esperado contributos decisivos para a maximizaçáo dos impactos desejados, nas pessoas e nas comunidades.

Esta demonstração de vitalidade surge, contudo, eivada de contradiçóes e acompanhada de falta de sentido integrador. Ao dirigir as políticas públicas a grupos com maiores défices, destinando-as a promover-lhes a empregabilidade, os estados acabam por se debater com os efeitos algo limitados destes investimentos, náo parecendo interessados em perceber que, no acesso e sucesso ao mercado de trabalho, a formação pode ser condição necessária, mas nunca será suficiente. A condição social dos diferentes agentes, as dinâmicas de interesses e poder em que eles se encontram sucessivamente envolvidos e os condicionalismos de desempenho das economias serão sempre determinantes em todos estes processos. Depois, se é verdade que a produção científica deste domínio se tem vindo a multiplicar e a diversificar, o que se verifica, na prática, é uma influência predominante das investigaçóes, modelos e contributos, oriundos dos domínios das ciências da gestáo e da administraçáo.

Numa breve síntese de toda esta evolução de práticas e conhecimento poderemos dizer que, se num primeiro momento foi a militância e boa vontade de pessoas que, na intenção de fazer chegar o conhecimento e a cultura aos que dela estavam afastados, procuravam construir verdadeiros movimentos sociais de luta pela igualdade de direitos e deveres, numa segunda fase, foi também a necessidade de todos (as) dominarem um conjunto de saberes e competências cada vez mais alargado e em necessidade de constante renovação, com o consequente reconhecimento social, que levou os poderes, públicos e privados, e os mais influentes organismos internacionais, como a UNESCO, a Organizaçáo para a Cooperaçáo e Desenvolvimento Económico (OCDE) e o Conselho da Europa, a defenderem uma aposta numa educação e formação, que deve contribuir para desenvolver a autonomia e o sentido de responsabilidade das pessoas e das comunidades, reforçar a capacidade de fazer face às transformaçôes da economia, da cultura e da sociedade no seu conjunto, promover a coexistência, a tolerância e a participação consciente e criativa dos cidadáos na sua comunidade, permitindo, em suma, que as pessoas e as comunidades assumam o controlo do seu destino e da sociedade para enfrentarem os desafios do futuro.

Como a prática nos demonstra, nunca, como hoje, a Educação e a Formação para pessoas adultas foi táo necessária, porque nunca, como hoje, foi táo obrigatório provocar as mudanças essenciais. Por isso mesmo é preciso repensá-la, na especificidade das experiências que pode proporcionar e na coerência do seu corpus teórico, como veículo mediador de verdadeiras transformaçóes individuais e sociais. Neste alerta geral têm vindo a gerar-se alguns consensos que, naturalmente, partilhamos. Referimos, aqui, apenas dois: o primeiro apela a um reforço da dimensão crítica como forma de progressiva libertação 
de condicionalismos que limitam o exercício pleno de uma cidadania planetária total, activa e informada, por parte de todas as pessoas, no sentido de uma garantia plena de igualdade de direitos, deveres e oportunidades; o segundo invoca a necessidade de alguma desvinculação das sucessivas tarefas ciclópicas que lhe foram sendo atribuídas, criando condiçóes para que ela possa contribuir para a construção de um novo ethos civilizacional, talvez mais contido em termos de poder, mas mais sintonizado com o mundo e com a vida das pessoas e comunidades.

\section{A Educação e Formação de Adultos em Portugal}

Em termos muito gerais, em Portugal, todos estes movimentos e debates tiveram efectivas repercussóes, embora com resultados sempre algo limitados. A verdade é que a educação, na mais ampla diversidade das suas propostas e práticas, foi tendo, ao longo dos tempos, alguma dificuldade em se constituir como uma necessidade real da generalidade dos portugueses. Um bom exemplo desta verdadeira inaptidão, para fazer chegar a educação às pessoas, pode ser encontrada na dificuldade em generalizar o acesso à instrução primária. Apesar de ter sido criada no consulado do Marquês de Pombal e tornada obrigatória e gratuita pela Carta Constitucional de 1826, apenas no início da segunda metade do século vinte conseguiu, efectivamente, envolver a totalidade das crianças em idade escolar. Como consequência destes repetidos insucessos, o nosso país não só registava, à entrada do século vinte e um, níveis muito baixos de escolaridade da população, como averbava um século de atraso em relação à generalidade dos países europeus, no que respeita à taxa de alfabetização (Alcoforado, 2008).

Tudo isto foi acontecendo, bom grado a qualidade dos discursos produzidos, da ousadia política de alguns textos legais, da generosidade de muitas iniciativas e da multiplicação de um número considerável de práticas, ao longo dos últimos cento e cinquenta anos. Se para o liberalismo português, principalmente o de inspiração mais republicana, uma transformaçáo da sociedade, assente numa nova ordem social, apenas se conseguiria com cidadãos ilustrados, curiosos, sensíveis às artes e à literatura e frequentadores de associaçóes e museus (Alcoforado \& Alcoforado, 2011), ainda durante a monarquia liberal, a acção abnegada de pessoas e instituiçóes interessadas na promoção de ideias de igualdade e democracia e a dinâmica gerada pelos movimentos de associativismo operário emergentes acabaram por constituir o impulso decisivo à consolidação da ideia de uma necessidade generalizada de aposta na Educação de Adultos.

Com a implantação do novo regime, recrudesceu a vontade política e multiplicaram-se as iniciativas da sociedade civil em prol da educação da população adulta. No entanto, apesar do inquestionável voluntarismo e do repetido enunciar de uma vontade humanitária e patriótica para enfrentar definitivamente este recorrente problema, a primeira república havia de chegar ao fim sem que o essencial do trabalho necessário fosse, sequer, iniciado.

Já na década de cinquenta do século vinte, no quadro de uma vontade de participação no desenvolvimento generalizado do mundo ocidental, o regime ditatorial e unipessoal, que marcava a segunda república portuguesa procurou, no âmbito da sua orientaçáo ideológica dominante, desenvolver um conjunto de iniciativas com impacto significativo na Educação de Adultos, integrado num muito mais vasto e ambicioso Plano de Educação Popular, destinado, como se dizia no preâmbulo do texto legal que o criava, não só 
"a divulgar os conhecimentos e as primeiras letras, mas ainda, e na medida do possível, a valorizar e a completar a formação moral e espiritual do nosso povo”. Iniciou-se, então, uma "uma intensíssima campanha, que teve o apoio de praticamente todo o país, desde o Episcopado até à Imprensa, desde as empresas até aos indivíduos” (Ruas, 1978, p. 291). Se é verdade que a intenção de fazer aprovar no exame final de instrução primária cerca de um milhão de pessoas analfabetas, particularmente as que se situavam no escalão etário entre os 15 e os 35 anos, ficou muito longe de ser conseguida, e se é igualmente verdade que esta campanha surgiu e se desenvolveu no "quadro típico dos regimes que procedem à estatização intensiva e extensiva da sociedade civil” (Patrício, 1982, p. 69), com um entendimento muito redutor de alfabetização (Carvalho, 1986), adoptando conteúdos e metodologias completamente escolares e infantilizadas, cujo exemplo mais paradigmático era exactamente o tipo de exames a que eram submetidos os adultos, náo podemos deixar de registar os recursos mobilizados, com uma dimensão até então única, na história da educação de adultos em Portugal, com resultados nada negligenciáveis. Para o poder político dominante ficou a sensação de dever (mais ou menos) cumprido, assumindo-se com orgulho a dimensão dos resultados conseguidos e a impotência para envolver os públicos que, apesar de todos os esforços, não tinha sido possível atingir.

Concomitantemente a estas iniciativas políticas, as décadas de cinquenta e sessenta acabaram por ver surgir, nalguns casos também em consequência da Campanha, um conjunto de dinâmicas governamentais (distribuídas por diversos ministérios) e não governamentais (Obra das Mães, Liga Agrária Católica e Graal, por exemplo), que foram mantendo, em particular estas últimas, a preocupação de uma acção educativa militante, para públicos diversificados, em diferentes contextos, mormente nas zonas rurais e do interior, onde apenas se tinham sentido efeitos muito ténues do esforço oficial da campanha (Alcoforado, 2008).

Apesar destas dinâmicas, a implantação da democracia e consequente institucionalização da terceira república, deu corpo a um generalizado coro de críticas ao regime deposto pela constatação da inépcia revelada no campo da educaçáo das pessoas adultas. Foi o momento de se mobilizarem esforços e vontades, materializado num conjunto de práticas organizadas à volta de duas correntes (Silva \& Rhodes, 1998, p. 20): a primeira, "visível em iniciativas de carácter pontual, como a Campanha de Dinamizaçáo, o Plano Nacional de Alfabetização e algumas acçóes no âmbito do Serviço Cívico Estudantil, aposta numa conversão ideológica, assente numa lógica de dinamização do Centro para a periferia; a segunda, associada ao modelo da educação popular, procurou, como modo de conseguir a consciencialização e emancipação dos sectores sociais desfavorecidos, inserir a educação de adultos nos movimentos populares e promover a qualidade dos processos educativos".

Se a primeira corrente se esvaziou na efemeridade do Período Revolucionário em Curso (PREC), a segunda corrente manteve-se política e teoricamente influente, quer na actividade da Direcçâo-Geral da Educação Permanente (DGEP), ao longo dos anos de 1975 e 1976 (Alcoforado, 2008), quer assumindo um papel decisivo aquando da elaboração, em 1979, do Plano Nacional de Alfabetização e de Educação de Base de Adultos (PNAEBA), desenvolvido pela DGEP, na sequência da aprovação, pela Assembleia da República, da Lei no 3/79 de 10 de Janeiro. Esta Lei, aprovada por unanimidade, representava para a Educação de Adultos, quer a adesão a modelos teóricos específicos, entretanto em construção, quer às ideias dominantes nas conferências internacionais promovidas pela UNESCO. Um projecto esperançoso que parecia reunir, como acreditava o Director Geral da Educação Permanente, Alberto Melo, "todas as condiçóes necessárias e suficientes para, 
pelo menos no âmbito da alfabetização e educação de base de adultos, se desenvolver uma prática inovadora, a muitos títulos inédita, de convergência criadora entre os princípios da abertura do acesso, os da educação permanente e os da educação popular" (Silva, 1990, p. 34), mas que se diluiu na falta de disponibilidade de recursos, tendo sido abandonado, poucos anos depois, sem que os resultados alcançados fossem minimamente significativos, face aos objectivos propostos.

Em 1985, Portugal embarcou na grande aventura europeia expondo, com evidente crueza, os efeitos que todas estas causas tinham motivado. Contudo, se era gritante o nível excessivamente baixo das nossas taxas de escolarização e das nossas qualificaçóes, para os nossos parceiros de bloco económico, a principal debilidade dos nossos indicadores estatísticos residia na baixa produtividade da população activa. Surpreendentemente, a nova Lei de Bases do Sistema Educativo, expressão da mais ambiciosa reforma que a democracia promovia, no domínio da educação, remeteu a educaçáo de adultos para a periferia das suas prioridades, limitando a oferta a duas valências pouco adequadas às características da procura: o ensino recorrente e a educação extra-escolar.

Nestas circunstâncias, exceptuando alguns projectos inovadores de investigação-acção e de desenvolvimento local, as práticas educativas para adultos reorganizaram-se à volta da aposta impressiva na formação profissional, realizada no âmbito dos quadros comunitários de apoio. Se é verdade que o sistema português de formação profissional tinha sido criado na década de sessenta, limitava-se, até então, a disponibilizar respostas ultrapassadas pela realidade, quase completamente estatais, pouco eficazes, muito burocratizadas, onerosas e com resultados pouco conseguidos (UNESCO, 1982). Por isso, e com os objectivos enunciados de diminuir a diferença de produtividade dos trabalhadores portugueses, em relação aos seus congéneres dos restantes países da Comunidade Económica Europeia, e de contribuir para a transformação progressiva dos nossos modelos produtivos, assistiu-se ao aumento exponencial de acçôes de formação, organizadas por centros estatais, privados e protocolares, empresas, associaçôes empresariais e, entre outras entidades, associaçóes sindicais, num total que, na vigência dos primeiros quinze anos de funcionamento, pode ter envolvido, segundo números das estruturas de gestão dos fundos comunitários, um número superior a quatro milhóes de pessoas (Alcoforado, 2000).

Estando, ainda, por fazer uma avaliação circunstanciada deste investimento e das práticas que proporcionou e podendo nós aceitar, facilmente, os importantes impactos positivos que elas tiveram nas pessoas, não podemos deixar, contudo, de assinalar que o grande objectivo ficou, mais uma vez, muito distante: não só o contributo para uma mudança dos modelos produtivos foi pouco significativo, como também a diminuição da diferença negativa registada na produtividade dos trabalhadores portugueses não sofreu alteraçóes dignas de uma avaliação positiva. Também mais uma vez, apesar de algumas experiências de formação de referência, as práticas estiveram muito afastadas do conhecimento específico produzido no âmbito deste domínio científico, desenvolvendo-se muito mais numa lógica baseada numa oferta do tipo "cardápio", tendente a maximizar o aproveitamento dos recursos disponibilizados e a formalizar a emergência de um generalizado mercado de formação e aprendizagem.

No final do século XX assistimos à tentativa de conjugar duas ideias, aparentemente inatacáveis: a conciliação da educação e da formação, até aí quase sempre de costas voltadas; a tentativa de acolher a agenda definida pelos países membros da UNESCO, na última cimeira do século, realizada em Hamburgo. Aproveitando a disponibilidade da Uniáo Europeia para apostar na competitividade da sua economia, baseando-a no conhecimento 
e na mobilidade dos trabalhadores, criou-se, mais uma vez, a esperança de que, finalmente, o nosso país poderia implementar uma política pública coerente e integrada de educação e formação de adultos. Esta confiança começou, desde logo, pela criação da tâo, repetidamente, desejada e anunciada estrutura coordenadora e continuou com a formalização de um programa verdadeiramente inovador de desenvolvimento do campo de práticas, consagrando, pela primeira vez, uma metodologia bem estruturada de reconhecimento, validação e certificação de adquiridos.

Apesar disso, a nova Agência, após repetida mudança de identidade, transformou-se, revelando, será mais que justo assinalar, uma vitalidade pouco comum para as tradiçóes portuguesas, numa entidade dinamizadora de um contrato-programa que apostava decididamente na elevação dos níveis de escolaridade e de qualificaçáo de jovens e adultos. Rotulado de Iniciativa Novas Oportunidades (INO), este programa teve o grande mérito de colocar a EFA no centro dos debates, aumentar exponencialmente as estruturas e os profissionais da área, multiplicar os estudos e reconciliar muitas das pessoas tradicionalmente afastadas destas dinâmicas. Apresentada pelo Governo saído das eleiçôes legislativas de 2005 como o melhor contributo para a melhoria do desempenho da economia e o combate ao desemprego, a INO teria, segundo os discursos oficiais de apresentação (Alcoforado, 2008) dois pilares fundamentais: em primeiro lugar, fazer do ensino profissionalizante de nível secundário uma verdadeira e real opçáo, dando Oportunidades Novas aos jovens, envolvendo mais de seiscentos e cinquenta mil em cursos técnicos e profissionalizantes; o segundo pilar previa elevar a formação de base dos activos, dando a um milhão de pessoas que entraram na vida activa com baixos níveis de escolaridade, uma Nova Oportunidade para poderem recuperar, completar e progredir nos seus estudos.

Apresentada desta forma, esta iniciativa não deixa de se assumir como uma ideia atraente, na medida em que se constituiu como um desafio capaz de mobilizar vontades, reunir alguns consensos e trazer visibilidade para o campo de práticas. É indiscutível que, por razóes históricas e necessidades de resposta a uma procura individual e social, a possibilidade de elevação simultânea, ou particularizada, dos níveis de escolaridade e de qualificação profissional dos portugueses era uma solução desejável e necessária, não só por constituir uma velha aspiração da Educação e da Formação de Adultos, mas também pelo contributo necessário para o combate a um indesejável e hierarquizante elitismo formativo, introduzindo princípios de elementar justiça no reconhecimento das aprendizagens resultantes da acção, em diferentes tipos de espaços e tempos de vida (todos educativos!), valorizando os percursos individuais e colectivos.

No entanto, ao apostar todos os seus recursos nos processos de elevação da certificação escolar (mais conseguida) e profissional (muito menos conseguida) a iniciativa, ainda que tenha alcançado resultados muito significativos (foram publicamente referidos números que apontam para mais de um milhão e quinhentos mil envolvidos e mais de quatrocentos mil certificados) acabou por expor-se a diferentes tipos de críticas: primeiro, porque nunca evoluiu da estrutura de contrato-programa, não criando as condiçóes necessárias para a consolidação de opçóes políticas estruturantes e integradoras para este domínio; depois, porque, ao centrar-se demasiado nas certificaçóes escolares, deixou-se entender como uma oferta tendencialmente tituladora; por fim, porque se expôs a uma avaliação objectiva (empregabilidade e desempenho da economia) que muito dificilmente poderia cumprir.

Todos estes indicadores e consequentes reflexóes devem servir-nos para combater os pessimismos recorrentes e os optimismos inconsequentes. O caminho andado deve 
constituir-se como um ponto de não retorno, uma vez que a necessidade de uma aposta continuada na EFA é um dos temas mais consensualizados ao longo da nossa história, com particular incidência na mais recente. Será necessário, por isso mesmo, avançar desde já para uma nova geração de políticas e práticas! Atendendo ao passado e ao conhecimento, entretanto, produzido, será indispensável que esta aposta na certificaçáo se possa incluir numa direcção educativa e formativa holística e emancipatória, verdadeira característica identificadora de qualquer proposta educativa e de formação de adultos, conjugando uma progressiva autonomia dos sujeitos e grupos com uma praxis transformadora, que contribua, decisivamente, para alterar as formas de intervenção cidadá, a acção cultural, os modelos produtivos e a organização do trabalho e as relaçôes interindividuais nas diferentes comunidades onde as pessoas interagem, levando-as a assumir a condução da sua vida, individual e colectiva, com prudência e vontade decidida.

\section{A Educação e Formação de Adultos na Universidade de Coimbra e as razóes para este livro}

$\mathrm{Na}$ sequência dos repetidos apelos dos agentes envolvidos no diversificado campo de práticas que se podem incluir nesta área, as Universidades, um pouco por todo o mundo, foram assumindo a responsabilidade de produzir conhecimento, elaborar quadros teóricos e contribuir para a formação dos diferentes profissionais. A generalidade das Universidades portuguesas e a Universidade de Coimbra, em particular, responderam a este desafio, participando de forma activa neste movimento. Ainda na década de setenta do século vinte, no caso desta Universidade, e na sequência do reforço da área das Ciências da Educaçáo, foi iniciada, no âmbito da novel Faculdade de Psicologia e de Ciências da Educação, sob iniciativa e orientação do Doutor António Simões, a preocupação de abrir um campo de ensino e investigação neste domínio, que originaria, uns anos mais tarde, a formação de Licenciados, Mestres e Doutores, o desenvolvimento de vários projectos de investigação, a produção não despicienda de literatura científica e a colaboração com os diferentes organismos nacionais, com o objectivo de contribuir para formar alguns dos agentes necessários ao desenvolvimento sustentado deste campo de práticas.

Para além das actividades de investigação e ensino, a área de Educação e Formação de Adultos da Universidade de Coimbra, assumiu a responsabilidade de organizar encontros científicos que foram reunindo especialistas nacionais e internacionais, procurando sedimentar um hábito de reflexão conjunta que contribuísse para o reforço identitário dos profissionais e investigadores, a abertura a áreas contíguas de saber e a consolidação do prestígio de toda uma problemática em desenvolvimento. Estes encontros passaram também a ter uma ambição natural de impulsionar políticas e contribuir para introduzir a inovação necessária nos processos, procurando fornecer reflexôes e conhecimento que permitam optimizar as transformaçóes necessárias.

No dizer de António Simóes, Presidente da Comissão Organizadora das duas primeiras ediçôes destas Jornadas, em 1996 a comunidade científica reunia, em Coimbra, pela primeira vez, num momento em que a situação portuguesa, neste domínio, continuava a não ver "soprar ventos favoráveis", enquanto na abertura do segundo encontro, em 2001, se reconhecia que se respirava outro ar, constatando-se que a educaçáo de adultos começava a ter condiçôes para reanimar. Assistíamos, finalmente, à criaçáo de uma Agência Nacional para 
a Educaçâo de Adultos, mas tinha sido, antes dela, "o trabalho abnegado dos educadores que persistiram contra toda a falta de esperança; o labor dos intelectuais que fizeram da educação de adultos uma disciplina universitária respeitável; os centros de investigação, que encetaram estudos sérios sobre a variada problemática da educação de adultos”. Tudo isto tinha contribuído para que esta se impusesse aos políticos como uma necessidade inelutável dos nossos tempos e uma contribuição insubstituível para a sobrevivência. Em qualquer dos casos, contudo, se alertava para o perigo de um desenvolvimento unidimensional, contrário à identidade genética e à tradição da educação de adultos.

Em Fevereiro de 2011, desafiámos, novamente, todos os interessados nesta área de conhecimento e intervenção, a encontrarem-se em Coimbra. Este evento aconteceu num momento em que Portugal, no domínio da Educação e da Formação de Adultos, mobilizava investimentos inusitados e ambiciona metas impressivas, mas também, e por isso mesmo, numa altura em que necessita, como nunca, que esta multiplicação de práticas seja acompanhada das questôes de investigação mais necessárias, das reflexões críticas mais adequadas e dos debates mais pertinentes.

Este encontro, que envolveu na sua organização todos os Professores e Investigadores da Faculdade de Psicologia e de Ciências da Educação que, ao longo dos últimos anos estiveram, de algum modo, ligados às actividades da área da Educação e Formaçáo de Adultos (Joaquim Armando Gomes Ferreira, António Gomes Ferreira, Margarida Pedroso Lima, Cristina Coimbra Vieira, Albertina Lima Oliveira, Luís Alcoforado e Sónia Mairos Ferreira), contou com parcerias internacionais, nomeadamente da Chaire de Formation des Adultes do Conservatoire National des Arts et Métiers e da Revista Education Permanente, uma e outra, instituiçóes absolutamente incontornáveis na construção do prestígio que esta área de conhecimento e intervenção foi granjeando, contou, também, com a colaboração da Agência Nacional para a Qualificação e com o envolvimento da Faculdade de Psicologia e de Ciências da Educação da Universidade de Coimbra. Participaram neste evento mais de seiscentos e cinquenta investigadores e profissionais, tendo sido apresentadas mais de cem comunicaçóes, num questionamento informado, sem precedentes, sobre esta área de saber e este campo de práticas.

Este livro constitui um primeiro testemunho dessas participaçôes. Como estas Jornadas foram as primeiras a ser realizadas sem a intervenção directa do Doutor António Simóes, embora inspiradas pelo seu exemplo e pelas suas reflexôes críticas, este livro pretende constituir-se como um preito muito merecido, ao seu trabalho como Pedagogo e Investigador, ilustrando o dinamismo de uma área para a qual ele ajudou a granjear merecido reconhecimento. Usando uma linguagem freiriana, cada capítulo, ou conjunto de capítulos, com identidade própria, pretendem constituir-se como verdadeiros temas geradores, capazes de despoletarem uma problematização generalizada da unidade epocal em que a educação e formação de adultos, actualmente, se desenvolve.

Temos, aqui, à disposição do leitor, um conjunto considerável de trabalhos sobre um alargado leque de temáticas, centrais para o desenvolvimento desta problemática e deste campo de práticas. Assim, aos contributos conceptuais, eminentemente reflexivos e críticos, que atestam a complexidade e pluralidade de perspectivas Teóricas e Políticas existentes neste campo associam-se, neste volume, relatos de práticas e investigaçóes realizadas. Inaugura este volume uma interessante reflexão sobre a produção académica portuguesa em Educação de Adultos. Partindo de uma breve incursão histórica das fontes primárias e também de trabalhos de apropriação crítica e de recontextualização elaborados 
por investigadores portugueses, o autor presenteia-nos com uma síntese de tendências de reflexão e investigaçáo nesta área em Portugal, analisando criticamente a evolução operada neste âmbito e, em simultâneo, desafiando-nos a uma compreensão mais profunda dos desafios que permanecem numa área do saber ainda em amadurecimento no nosso país. No seio desta reflexão o autor salienta a obra pioneira de António Simóes. Num domínio com emergência tardia e, consequentemente, com limitada tradição educativa, política e também académica, quando comparado com a sua expressão noutros países da Europa ou América, este investigador contribuiu, de forma substantiva e continuada no decurso da sua carreira, para o seu reconhecimento e incremento da produção científica e pedagógica, sempre pautado por critérios de elevado rigor e profunda reflexão crítica. Segue-se, a este capítulo inaugural, uma pertinente reflexão sobre as transformações a nível das Políticas Educativas em Educação de Adultos, operadas no nosso país.

Nos capítulos seguintes são analisadas, a partir de perspectivas plurais de análise, temáticas tão diversas como a construçáo de projectos profissionais enquanto ferramenta-chave para o futuro das pessoas adultas, a orientaçáo no âmbito das transiçóes de carreira na adultez ou a adaptabilidade e orientação ao longo da vida. Os contributos subsequentes subordinam-se à compreensão, sustentada em distintos ângulos conceptuais e de investigação, das dinâmicas dos Centros Novas Oportunidades, nomeadamente no que respeita à acção e saberes dos técnicos; aos processos de Reconhecimento, Validaçáo e Certificação de adquiridos profissionais; ao(s) papel(eis) do órgão de gestáo dos estabelecimentos de ensino público e a sua relação com o Centro Novas Oportunidades; à relação entre a aprendizagem ao longo da vida e o bem-estar dos adultos em processo de RVCC de nível secundário. Reflecte-se, ainda, sobre a actividade profissional dos Mediadores nos Cursos de Educação e Formação de Adultos; a importância das histórias de vida; o Currículo integrado e a formação holística no âmbito dos Cursos EFA-NS-Certificação Escolar e a centralidade do aprender a aprender no processo RVCC.

Numa incursão histórica, o artigo seguinte reporta-se às Representaçôes do Plano de Educação Popular e da Campanha Nacional de Educaçáo de Adultos no Ensino Normal Primário de Coimbra, seguido de uma reflexão crítica sobre os princípios e desafios inerentes ao educar para a interculturalidade e cidadania. Integram, ainda, este volume, contribuiçóes várias sobre o Ensino Superior, em específico, os contextos e desafios que se colocam aos estudantes adultos neste nível de Ensino; a revolução operada em resultado do acesso de "novos públicos"; a sua Missáo e Filosofia segundo as perspectivas de Professores de uma Escola do Ensino Superior Politécnico. Ultima esta publicação, um capítulo dedicado à revisão das Políticas Públicas para Idosos e o Direito à Educação em Portugal e sobre a economia solidária, inovação social, empreendedorismo, desenvolvimento local.

Embora conscientes que a sua pluralidade, complexidade e riqueza não se esgotam nas reflexôes tecidas nesta produção, os trabalhos científicos nela constantes fornecem uma visão sumária das tendências actuais e prospectivas neste âmbito. O que se deseja é que este livro, como as Jornadas que o originaram, possam contribuir para uma educação e formação de adultos que, como escreveu o nosso Torga, ajude a furar os olhos do tempo, desafiando com o futuro que queremos construir, o amanhã que, todos os dias, nos anunciam. 


\section{Bibliografia}

Alcoforado, L. (2008). Competências, Cidadania e Profissionalidade. Limites e desafios para a construçâo de um modelo português de Educação e Formação de Adultos. Dissertação de Doutoramento. Faculdade de Psicologia e de Ciências da Educação da Universidade de Coimbra.

Alcoforado, L. (2001). O Modelo da Competência e os adultos portugueses não qualificados. Revista Portuguesa de Pedagogia, Ano 35 (1), 67-83.

Alcoforado, L. (2000). Educação de Adultos e Trabalho. Dissertação de Mestrado não publicada. Faculdade de Psicologia e de Ciências da Educação, Universidade de Coimbra.

Alcoforado, L. \& Vieira, C. M. C. (2007). A educação de pessoas adultas como promotora da igualdade de oportunidades entre homens e mulheres. Revista Portuguesa de Pedagogia, 41(3), 173-194.

Alcoforado, A. \& Alcoforado, L. (2011). Museu Machado de Castro, um projecto educativo de inspiração republicana. In Câmara Municipal de Coimbra, A República, os Museus e o Património (pp. 52-69). Coimbra: CMC.

Bhola, H. S. (1989). Tendances et perspectives mondiales de l'éducation des adultes. Paris: UNESCO.

Bogard, G. (1994). Education des Adultes. Un pari progressiste du Conseil de l'Europe. Etapes d'un Project (19601993). Estrasburgo: Conselho da Europa.

Canário, R. (1999). Educação de Adultos: Um campo e uma problemática. Lisboa: Educa.

Carvalho, R. (1986). História do Ensino em Portugal : desde a fundação da nacionalidade até ao fim do regime Salazar-Caetano. Lisboa : FCG

Charlot, B. \& Beillerot, J. (1995). La Construction des Politiques d'Éducation et de Formation. Paris: PUF.

Comissão Europeia. (1994). Crescimento, Competitividade, Emprego, os desafios e as pistas para entrar no século XXI. Livro Branco. Luxemburgo: CE.

Comissão Europeia. (2000). Memorando sobre a aprendizagem ao longo da vida. Bruxelas: CE.

Comissão Europeia. (2001). Tornar o espaço europeu de aprendizagem ao longo da vida uma realidade. Bruxelas: CE.

Correia, J. A. (2005). A Formação da Experiência e a Experiência da Formação num Contexto de Crise do Trabalho. In R. Canário, e B. Cabrito, Educação e Formação de Adultos: mutaçôes e convergências (pp.61-72). Lisboa: Educa.

Dave, R. H. (1979). Fundamentos de la Educación Permanente : aspectos metodológicos. In R. H. Dave, Fundamentos de la Educacion Permanente (pp. 21-57). Madrid: Santillana.

De Natale, M. L. (2003). La edad adulta, una nueva etapa para educarse. Madrid: Narcea.

DGEP. (1979). Plano Nacional de Alfabetização e de Educação de Base dos Adultos. Relatório Sintese. Lisboa: Ministério da Educação.

Dias, J. R. (1978). Introdução Histórica. In M. J. Gusmão e A. J. G. Marques. Curso sobre Educação de Adultos (pp. 9-57). Braga: Universidade do Minho.

Faure, E. \& al. (1974). Aprender a Ser. Lisboa: Bertrand.

Field, J. (2002). Lifelong learning and the new educational order. Londres: Trentham Books.

Finger, M. e Asún, J. M. (2003). A Educação de Adultos numa encruzilhada. Aprender a nossa saída. Porto: Porto Editora.

Freire, P. (1992). Pedagogia da Esperança: um reencontro com a Pedagogia do Oprimido. São Paulo: Paz e Terra.

Habermas, J. (2000). O Discurso Filosófico da Modernidade. Lisboa: Publicaçōes Dom Quixote.

Jarvis, P. (2001). O futuro da educação de adultos na sociedade de aprendizagem. Revista Portuguesa de Pedagogia, 35(1), 13-30.

Jobert, G. (2001). Idéologies et pratiques des premières générations de formateurs d'adultes. Education Permanente, $149,155-167$.

Lima, L. (2003). Formação e aprendizagem ao longo da vida: entre a mão direita e a mão esquerda de Miró. In Fundação Calouste Gulbenkian, Cruzamento de Saberes, aprendizagens sustentáveis (pp. 129-148). Lisboa: FCG.

Melo, A. \& al. (1998). Uma Aposta Educativa na Participação de Todos: Documento de Estratégia para o Desenvolvimento da Educação de Adultos. Lisboa: Ministério da Educação.

OCDE. (1996). Lifelong Learning for All. Paris: OCDE.

Oliveira, A. L. (2005). Aprendizagem auto-dirigida : um contributo para a qualidade do ensino superior. Dissertaçáo de Doutoramento. Faculdade de Psicologia e de Ciências da Educação da Universidade de Coimbra.

Oliveira, A. L. (2007). Quem são eles e como são eles? O caso dos adultos no ensino superior. Revista Portuguesa de Pedagogia, 41 (3), 43-76.

Osorio, A. R. (2003). Educación Permanente y Educación de Adultos. Barcelona: Ariel. 
Patrício, M. F. (1982). A Educação de Adultos em Portugal. In Universidade de Évora, Educação de Adultos no Alentejo, contributo para a formaçâo dos agentes educativos (pp. 33-79). Évora: Universidade de Évora.

Ruas, H. B. (1978). Educação de Adultos em Portugal, no Passado e no Presente. In M. J. Gusmão \& A. J. Gomes Marques, Educação de Adultos. (pp. 269-300). Braga: Universidade do Minho.

Silva, A. S. \& Rhodes, L. A. (1998). Educação de Adultos. In A. S. Silva. A Evolução do Sistema Educativo e o PRODEP. Estudos Temáticos. Volume III. Lisboa: ME.

Silva, A. S. (1990). Educação de Adultos. Educação para o Desenvolvimento. Rio Tinto: ASA.

Simôes, A. (1979). Educação Permanente e Formação de Professores. Coimbra: Almedina.

UNESCO. (1982). Para uma política de Educação em Portugal. Lisboa: Livros Horizonte. 

Série Documentos

Imprensa da Universidade de Coimbra

Coimbra University Press

2011

- U

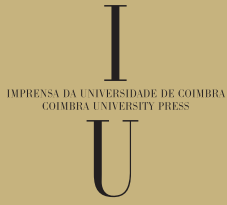

